\title{
Mapping of the Mouse Actin Capping Protein Beta Subunit Gene Marilyn C. Hart ${ }^{2}$, Yulia O. Korshunova ${ }^{3}$ and John A. Cooper ${ }^{1}$
}

Address: ${ }^{1}$ Department of Cell Biology and Physiology, Washington University School of Medicine, St. Louis, MO 63110, USA., ${ }^{2}$ Winona State University, Winona, MN 55987, USA. and ${ }^{3}$ Department of Genetics, Washington University, St. Louis, MO 63110, USA. E-mail: ${ }^{2}$ mhart@VAX2.WINONA.MSUS.EDU ${ }^{3}$ yuliak@sequencer.wustl.edu ${ }^{1}$ jcooper@cellbio.wustl.edu

Published: 27 July 2000

BMC Genomics 2000, I:I
Received: II July 2000

Accepted: 27 July 2000

The electronic version of this article is the complete one and can be found on-

line at http://biomedcentral.com//47/-2/64/I/I

\begin{abstract}
Background.: Capping protein (CP), a heterodimer of $\alpha$ and $\beta$ subunits, is found in all eukaryotes. $\mathrm{CP}$ binds to the barbed ends of actin filaments in vitro and controls actin assembly and cell motility in vivo. Vertebrates have three isoforms of CP $\beta$ produced by alternatively splicing from one gene; lower organisms have one gene and one isoform.
\end{abstract}

Results.: We isolated genomic clones corresponding to the $\beta$ subunit of mouse $\mathrm{CP}$ and identified its chromosomal location by interspecies backcross mapping.

Conclusions.: The CP $\beta$ gene (Cappb I) mapped to Chromosome 4 between Cdc42 and D4Mit3 I 2 . Three mouse mutations, snubnose, curly tail, and cribriform degeneration, map in the vicinity of the $\beta$ gene.

\section{Background}

Capping protein (CP) is a ubiquitous actin binding protein that regulates actin assembly and cell motility. CP is a heterodimer composed of $\alpha$ and $\beta$ subunits, each approximately $30 \mathrm{kD}$. Lower organisms, including Saccharomyces cerevisiae, Caenorhabditis elegans and Drosophila melanogaster, have one gene and one isoform for each of the $\mathrm{CP} \alpha$ and $\beta$ subunits $[1,2,3]$. Vertebrates contain three $\alpha$ subunit isoforms encoded by three different genes and three $\beta$ subunit isoforms $(\beta 1, \beta 2, \beta 3)$ produced from one gene by alternative splicing $[4,5,6]$.

\section{Results and Discussion}

To confirm the genomic complexity of the $\beta$ subunit of mouse CP, Southern blots of mouse genomic DNA were cleaved with several restriction enzymes and independently probed with mouse $\beta 1$ and $\beta_{2}$ cDNAs. The $\beta 1$ and $\beta_{2}$ probes each hybridized to one identical band. To obtain genomic clones that correspond to this pattern, a 129SV genomic library in the lambda FIXII vector (Stratagene) was screened using the complete $\beta 1 \mathrm{cDNA}$ as probe. Positive plaques were purified according to standard proce- dures [7] and the phage DNA isolated using DEAEcellulose [8]. Comparison of the hybridization pattern for the genomic clones with the mouse genomic DNA revealed that the patterns were identical, confirming the presence of a single $\beta$ gene in the mouse genome.

In chicken, the $\beta 1$ and $\beta 2$ isoforms have been described as the differentially spliced products of a single gene, with the $\beta 1$ cDNA containing a $113 \mathrm{bp}$ exon that is absent in the $\beta 2$ cDNA [4]. To determine if the murine $\beta 2$ isoform is spliced in a manner identical to that of chicken, the sequence of the $\beta 2 \mathrm{cDNA}$ was compared to the corresponding genomic region. Sequence comparison revealed that alternative splicing of the $\beta 2$ gene occurs in an identical manner in mice. The mouse intron is also 113 $\mathrm{bp}$ in length with the exon sequence and surrounding intron sequence containing the canonical splice donor (AGA) and acceptor (AGG) sites at either end of the intron. The human gene for CP $\beta$ has a similar structure, based on the sequence of clone HS657E11, located at Chr1 p35.1-p36.23, from the Sanger Centre (www.sanger.ac.uk/HGP/Chr1/). 
Jackson BSS Chromosome 4

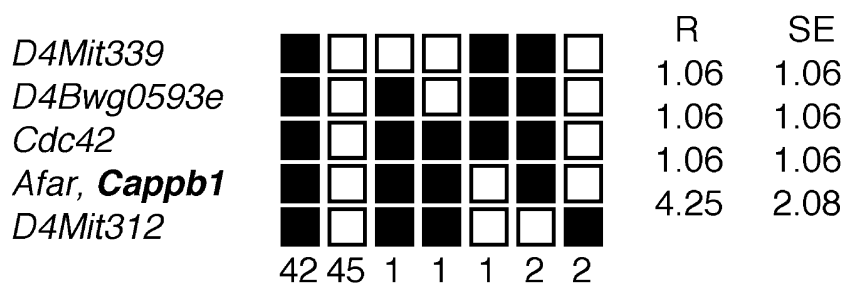

Figure I

Haplotype data for the mapping of the mouse CP $\beta$ gene showing a portion of Chromosome 4 with loci linked to Cappbl. Loci are listed in order with the most proximal at the top. The black boxes represent the C57BL6/] allele and the white boxes the SPRET/Ei allele. The number of animals with each haplotype is given at the bottom of each column of boxes. The percent recombination $(R)$ between adjacent loci is listed to the right, with the standard error (SE) for each R. Missing typings were inferred from surrounding data where assignment was unambiguous.

To determine the chromosomal location of marine Cappb1, we identified interspecies variations of genomic sequences and mapped their chromosomal locations using an interspecies backcross panel from Jackson Laboratory [9]. The mapping panel is anchored to maps from crosses by various known genes, retroviral loci, and the $D \# M i t$ loci. The strain distribution pattern of each polymorphism in the interspecific backcross was determined and used to position the Cappb1 gene on the map (Figure 1).

A region corresponding to the 3' UTR of the Cappb1 gene was PCR-amplified using parental genomic DNA and gene-specific primers (5'TTTTCCCTCTTCCTTTCC 3 ' and 5'ACTCCAAGCAACTCCCACAC3'). Direct sequencing of the PCR product identified two polymorphisms: 1) Nucleotides 1220-1224 (referring to Genbank Acc. No. U10406), C57BL/6J: CCCCC; M. spretus: CCCC, 2) Nucleotides 1336 1349: C57BL/6J: GGTGTGTGA-GAGAA and M. spretus: GGTGTGTGAAAGAGAA. Genomic DNA from the panel of 94 backcross animals was PCR-amplified using the aforementioned primers and then hybridized via dotblot analysis with four oligonucleotides: 5'AAGGAAGGGGGACAGG3', 5'AAGGAAGGGGACAGG3', 5'CTCTCACACA3', 5 'CCACACACTTTCTCTT 3 ', which specifically bound to each of the four polymorphic sequences, respectively. The resulting allele patterns were compared to those of other loci previously mapped in this cross to detect linkage.

The CP $\beta$ gene (Cappb1) mapped to Chromosome 4 between D4Mitl6 and D4Mit13. Additional linkage information is available at http://www.jax.org./resources/ documents/cmdata. Mouse Genome Database accession numbers for the mapping data are J:55295 (Cappb1).
The order of loci (with recombination distances in centimorgans, $\mathrm{cM}$ and standard error) and intergenic distances for the CP $\beta$ gene (Figure 1 and 2) is as follows: Cappb1: Nearby genes include Cdc42 and Afar. D4Mit339- (1.06 $\pm 1.06 \mathrm{cM})-D 4 B w g 0593 e-(1.06 \pm 1.06 \mathrm{cM})-C d c 42-$ $(1.06 \pm 1.06 \mathrm{cM})$-Afar, Cappb1- (4.25 $\pm 2.08 \mathrm{cM})-$ D4Mit312.

To determine if the Cappb1 gene was equivalent to a locus that had previously been mapped thereby identifying a possible association with an existing mutant, the Jackson Laboratory Mouse Genome Database (MGD) and the Mouse Chromosome Committee Report (1999) were scanned for loci that lie within $10 \mathrm{cM}$ of the map positions of Cappb1. snubnose ( $(s)$, curly tail (ct), and cribriform degeneration (cri) are candidate mutants for Cappb1.

\section{Jackson BSS Chromosome 4}

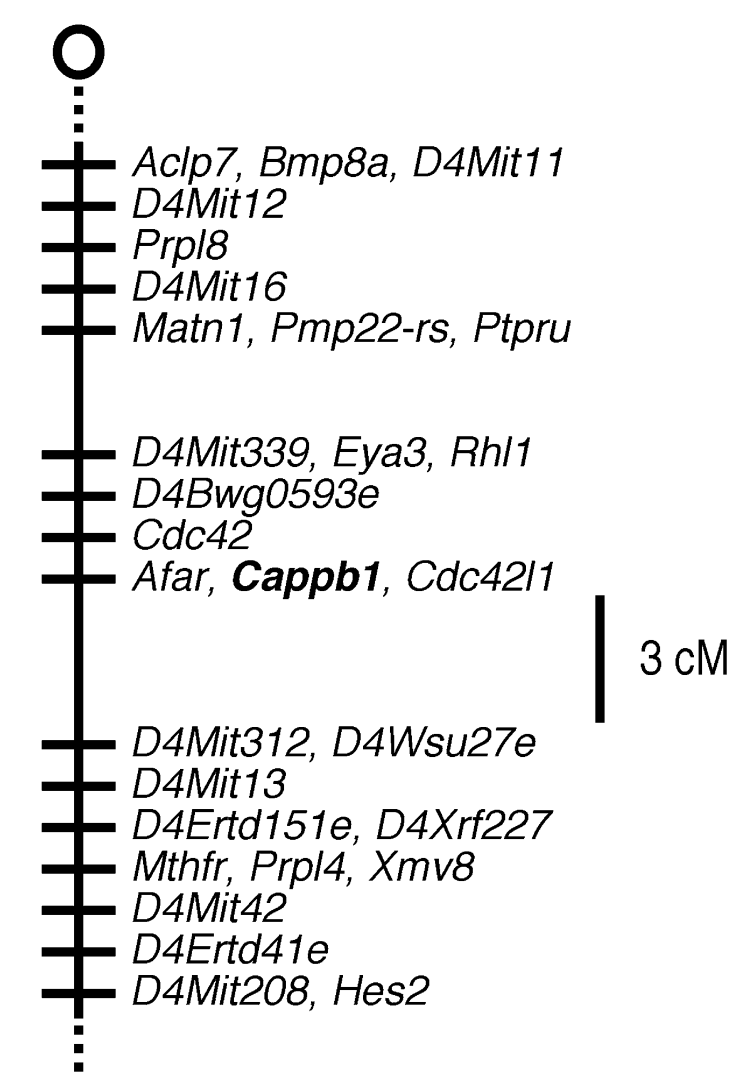

Figure 2

Map from the Jackson BSS backcross showing part of Chromosome 4. The centromere is toward the top. Loci mapping to the same position are listed in alphabetical order. Missing typings were inferred from surrounding data where assignment was unambiguous. Raw data from Jackson Laboratory were obtained from [www.jax.org./resources/documents/ cmdata]. 
The likelihood that Cappb1 and sno, ct and cri map to the same position was evaluated by determining the confidence intervals associated with their map positions (Figure 3). Cappb1 (66.8 cM, MGD) was mapped relative to the well-established anchoring locus D4Mitl3 $(71 \mathrm{cM}$, MGD), with 5 recombinants in 94 backcross samples. At 95\% confidence, the upper and lower limits are 2.5 and 12.5 , respectively [10]. sno (58.3 cM, MGD) was mapped relative to tyrosinase related protein, Tyrp1, (39 cM, MGD) with 92 recombinants in 535 backcross animals providing confidence limits of 14 and 20.5 [11]. cri (69 cM, MGD) was mapped relative to Tyrp1, but raw mapping data were not reported, which precludes determination of the confidence limits [12]. ct (69 cM) was mapped relative to D4Mitl3 with 26 recombinants in 272 backcross animals providing confidence limits of 6.6 and 13.7. The confidence intervals of $c t$ and Cappb1 overlap, indicating that equivalency of these loci are not ruled out by the mapping data. Because the confidence interval of the mapping of $\mathrm{cri}$ could not be determined, the equivalency of cri and Cappb1 cannot be ruled out. The confidence intervals of sno and Cappb1 do not overlap, indicating that these loci are not equivalent.

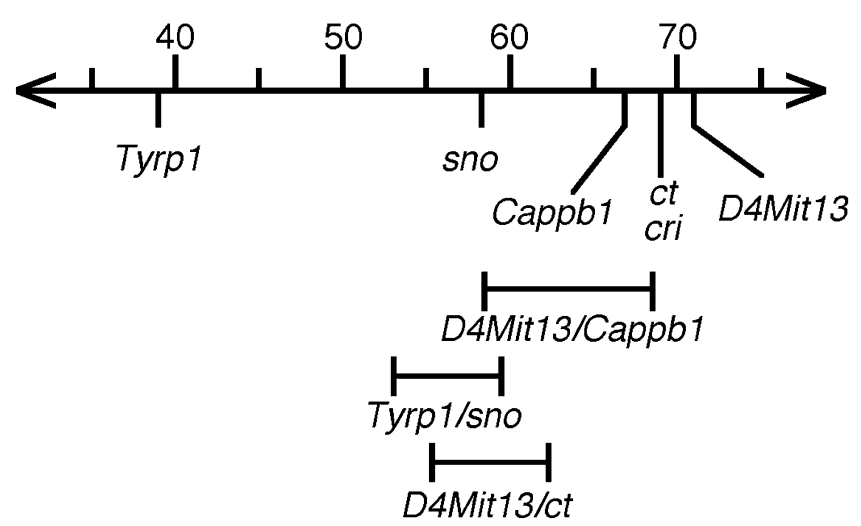

Figure 3

The confidence limits of the mapping of Cappb I and its candidate genes: snubnose (sno), curly tail (ct), and cribriform degeneration (cri). The chromosomal region where Cappbl and the candidate genes reside is depicted. The MGD map positions are indicated above. 95\% confidence intervals based on specific mapping experiments, discussed in the text, are indicated below.

Analysis of the mutant phenotype for $c r i$ and $c t$ is a way to evaluate their potential roles. Mutations in cri have a severe neurological defect that can be traced to vacuolar degeneration in white and gray matter of the spinal cord and brainstem [13]. Mutations in $c t$ have some degree of spina bifida which results in a curly tail and occasionally, exencephaly [14]. Mutations in sno are recognized by their short noses and have spina bifida occulta in their lumbar, posterior thoracic and sacral vertebrae [15]. Ad- ditional studies will be necessary to determine whether these loci encode or map to Cappb1.

Comparative gene mapping between mouse and human has revealed numerous regions of homologous genome organization [16]. The mapping of Cappb1 supports the evolutionary conservation between the two species. The chromosomal assignment of the mouse CP $\beta$ gene to Chromosome 4 is consistent with the localization of the human CP $\beta$ gene to chromosome 1 position $\mathrm{p} 36.1$. These regions of the mouse and human chromosomes have conserved synteny.

\section{Conclusions}

The CP $\beta$ gene (Cappb1) mapped to Chromosome 4 between Cdc42 and D4Mit312. Three mouse mutations, snubnose, curly tail, and cribriform degeneration, map in the vicinity of the $\beta$ gene.

\section{Acknowledgments}

We thank Lucy Rowe and Mary Barter of the Jackson Laboratory for their advice and assistance with the backcross panels and the interpretation of the genetic mapping data. This work was supported by a grant from NIH (GM38542). M.H. was supported by an American Heart Association PostDoctoral Fellowship and was a member of the Lucille P. Markey Pathway for Human Pathobiology. J.A.C. was an Established Investigator of the

American Heart Association.

\section{References}

I. Waddle JA, Cooper JA, Waterston RH: The $\alpha$ and $\beta$ subunits of nematode actin capping protein function in yeast Molecular Biology of the Cell 1993, 4:907-917

2. Hopmann R, Cooper JA, Miller KG: Actin organization, bristle morphology, and viability are affected by actin capping protein mutations in Drosophila. Journal of Cell Biology 1996, | 33:1293-1305

3. Amatruda JF, Cannon JF, Tatchell K, Hug C, Cooper JA: Disruption of the actin cytoskeleton in yeast capping protein mutants Nature 1990, 344:352-354

4. Schafer DA, Korshunova YO, Schroer TA, Cooper JA: Differential localization and sequence analysis of capping protein $\beta$-subunit isoforms of vertebrates. Journal of Cell Biology 1994, I 27:453465

5. Hart MC, Korshunova YO, Cooper JA: Vertebrates have conserved capping protein alpha isoforms with specific expression patterns Cell Motil Cytoskeleton 1997, 38:120-132

6. von Bulow M, Rackwitz HR, Zimbelmann R, Franke WW: CP $\beta-3$, a Novel Isoform of an Actin- Binding Protein, is a Component of the CytoskeletalCalyx of the Mammalian Sperm Head. Experimental Cell Research 1997, 233:216-224

7. Sambrook J, Fritsch EF, Maniatis T: Molecular Cloning. A Laboratory Manual., Second edn. Cold Spring Harbor, NY: Cold Spring Harbor Laboratory Press; 1989.

8. Helms C, Dutchik JE, Olson MV: A lambda DNA protocol based on purification of phage on DEAE-cellulose. Methods Enzymol 1987, 153:69-82

9. Rowe LB, Nadeau JH, Turner R, Frankel WN, Letts VA, Eppig JT, Ko $\mathrm{MSH}$, Thurston SJ, Birkenmeier EH: Maps from two interspecific backcross DNA panels available as a community genetic mapping resource Mammalian Genome 1994, 5:253-274

10. Silver LM: Mouse genetics: concepts and applications. New York: Oxford University Press; 1995

II. Hollander WF: Research notes: testcross linkage data for snubnose and brown Mouse News Letter 1966, 34:

12. Green MN: Cribriform degeneration (cri). Mouse News Letter 1972, 47:37-

13. Green MC, Sidman RL, Pivetta $\mathrm{OH}$ : Cribriform degeneration (cri): a new recessive neurological mutation in the mouse Science 1972, 176:800-803 
4 BMC Genomics (2000) 1:1

14. Gruneberg H: Genetical studies on the skeleton of the mouse. VIII. Curlytail. J Genet 1954, 52:52-67

15. Hollander WF: Genetic spina bifida occulta in the mouse Am J Anat 1976, I46:173-179

16. O'Brien SJ, Womack JE, Lyons LA, Moore KJ, Jenkins NA, Copeland NG: Anchored reference loci for comparative mapping in mammals Nature Genetics 1993, 3:103-II2 